Plant Pathology and Plant Pathogens is a second edition of a book published in 1977. It is essentially similar to its predecessor, but brought up to date and with a number of minor improvements (longer and better reading lists at the end of each chapter to a total of some 100 references, and an expanded and greatly improved Chapter 9 now renamed "Host-Pathogen Specificity"). The book deals successively with microbial pathogens, their structure and function, infection and colonization, diseases in populations and at the whole plant, cellular and molecular levels, with specificity and with disease control. It is well illustrated, the 90 or so figures being simple yet informative, and the text is clear and interesting. The book is a useful survey of the general features of diseases caused by microorganisms and will be attractive to students; it would, however, be improved by some reorganization of the contents of the three chapters dealing with the diseased plant and with pathogens.

Manners's Principles of Plant Pathology covers the same ground but is quite different in content and presentation. There are five parts, successively on causes, physiology, genetics, epidemiology and control of plant diseases. This is a straightforward, well tried and probably the best sequence. Each part is divided into sections, the order of which is again logical, and the text is well written and easy to absorb. There are no more than 36 diagrams and photographs, and 14 tables; quite a few of each are not so illustrative as they should be to balance the general quality of the text. There is a very useful glossary, but while the list of some 600 references may suit teachers, students will find it formidable. This again is an attractive book, and I would hesitate to recommend to a student which of the two books on plant pathology to buy if only one of them can be.

R.K.S. Wood is Professor of Plant Pathology and Head of the Department of Pure and Applied Biology at Imperial College, University of London.

\section{Forms and functions in the plant sciences}

\section{James F. Sutcliffe}

\section{Plant Anatomy, 3rd Edn.}

By A. Fahn.

Pergamon: 1982. Pp.544.

Hbk £30, \$60;

pbk $£ 13.50, \$ 27$.

Agricultural Plants.

By R.H.M. Langer and G.D. Hill.

Cambridge University Press: 1982.

Pp.343. Hbk £20, \$39.95; pbk £7.95, $\$ 15.95$.

Plant Growth Substances Including

Applications in Agriculture.

By H.N. Krishnamoorthy.

Tata McGraw-Hill: 1982. Pp.214. £7.75, $\$ 12.50$.

AlTHOUGH anatomy does not feature prominently nowadays in botanical teaching, a sound knowledge of plant structure is still important. Anyone brought up on Professor Esau's splendid Plant Anatomy and Anatomy of Seed Plants may wonder whether an alternative textbook is needed. The fact that Professor Fahn's book is now in its third edition supplies the answer. The text of the book - originally translated from Hebrew by Sybil Broido-Altman - is clear and concise, and covers the development of structures as well as providing accurate descriptions of mature tissues. One is not overwhelmed by botanical terms, the most important of which are found in a useful glossary. There is an up-to-date list of key references to research and review papers at the end of each chapter, and extensive subject and author indexes are also included.

The 21 chapters are divided into four main groups covering mature tissues, the primary and secondary vegetative bodies, and reproductive organs. Attention is given mainly to angiosperms and, apart from a description of gymnosperm wood, other plants receive scant attention. The text is well-illustrated by numerous line drawings and photographs including some excellent recent scanning electron micrographs.

There is a brief introduction to plant anatomy as a prelude to Langer and Hill's Agricultural Plants, but the book consists mainly of some 300 pen-portraits of plants used in agriculture. It deals with their history, cultivation and uses as well with some more botanical aspects. There are pleasing and accurate-line drawings to aid identification and to illustrate features of special interest. The book is confined mainly to temperate crops; tree species and plants of predominantly horticultural interest are excluded.

The plants are arranged in families starting with monocots. More than half the book is taken up with descriptions of members of the Gramineae and Leguminosae while some families - the Malvaceae and Papaveraceae, for example - are represented by only a single genus. A final chapter, which seems to be rather out of place, deals briefly and somewhat superficially with the physiological basis of yield; among the topics covered are plant development, crop photosynthesis and the distribution of dry matter. The reader will search in vain for any information about the role of growth regulating substances in these processes, although the gibberellins are mentioned briefly earlier in the book in connection with the germination of cereal grains and malting of barley.

This deficiency is remedied by H.N. Krishnamoorthy in Plant Growth Substances. The treatment, however, is unexciting. Each of the groups of growth regulators - auxins, gibberellins, cytokinins, abscisic acid, ethylene and retardants - is dealt with systematically in a separate chapter covering discovery, history, extraction, assay, biosynthesis, physiological effects and mode of action. While this approach has its merits, particularly for the student who likes to have information cut and dried, it suffers from the disadvantage that interactions between different growth regulators tend to be overlooked. To discover the integrated role of the various groups of substances in a par- ticular process, for example flowering, requires a good deal of effort even with the help of the subject index.

The standard of production of Plant Growth Substances compares unfavourably with the other two books reviewed here. No doubt the resultant saving in cost will be welcome to students, not only in the Third World, but the lack of photographs and the poor quality of the line-drawings detract seriously from the book's attractiveness as a student text.

James F. Sutcliffe has retired recently as Professor of Plant Physiology at the University of Sussex.

ADVERTISEMENT
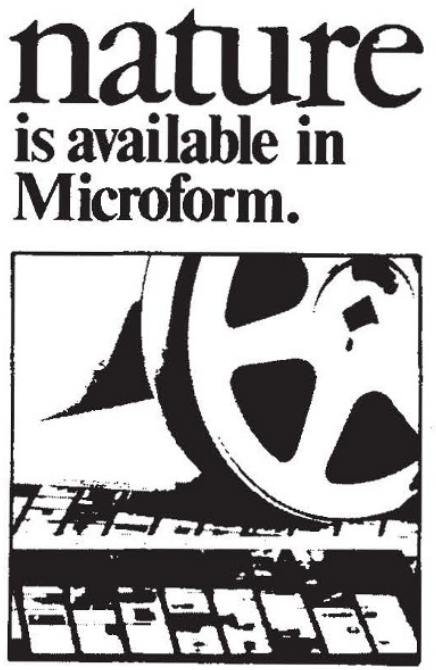

University Microfilms International

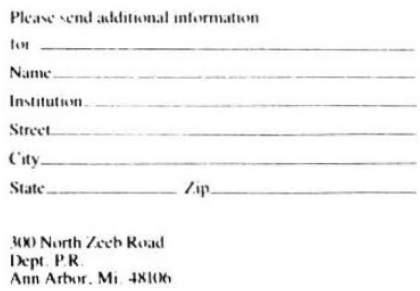

lept PR.

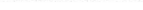

